\title{
4 \\ Teaching Gender to Prevent AIDS
}

I can't feed my baby beard hair to make her grow a beard and become a man. She is a girl. This won't change. That is sex. Jenda is what you learn in life that gives you power. For example, you learn to be a pilot or you learn to be a nurse. Jenda is important because you can change it. If you are sinful, you can become a religious man. If you are a woman who plays cards and gambles, you can change and become a woman who plants sweet potatoes. Jenda is the things you can change.

-ANNA, AN AIDS EDUCATOR

During a week-long AIDS Awareness workshop at a health center not far from Tari, this was one of the ways the instructor explained the difference between sex and gender to the participants. As noted in chapter 3, AIDS education in the Tari area in the early 2010 s was animated by a "will to improve" (Li 2007) gender relations, and especially marital relations. "Improvement" entailed both promoting gender equality and equipping married couples with communication and other skills for making marital relations more harmonious. Educating people about the difference between sex (as biologically based) and gender (as culturally constructed) seemed to be an important step in this work of improvement.

I was initially flummoxed by this goal of teaching workshop participants, many of whom had very little formal education and were not fluent in English, about the difference between sex and gender, terms that have no equivalent in Huli or Tok Pisin. What did this have to do with preventing HIV transmission?

The logic behind this pedagogical aim had two parts. The first is that gender inequality drives the global HIV pandemic and makes women and girls disproportionately vulnerable to infection. Factors such as women's early marriage, their lower educational and employment levels, their economic dependency and lesser control over land and other assets, and their inability to control when and how sex takes place all contribute to their greater vulnerability, as do masculine 
prestige structures that reward men for acquiring many sexual partners (Mannell 2010, Mukherjee and Das 2011, Hirsch et al. 2010). In Papua New Guinea, all these factors, as well as very high rates of sexual and domestic violence (Borrey 2000, Lepani 2008, MSF 2010, Jolly et al. 2012, Biersack et al. 2016), have spurred AIDS prevention approaches that focus on confronting and dismantling gender inequality (Seeley and Butcher 2006, Hammar 2010). Second, confronting and dismantling gender inequality is thought to require (among many other things) conveying the cultural constructedness of gender roles and making visible the part that societies play in valuing, and granting power to, the male gender over the female gender. Thus, to combat women's HIV vulnerability, one must understand that this vulnerability is created, in part, by gendered roles and values, which, since they are not determined by biological sex, can (and should) be changed.

During this AIDS education workshop, the concept of gender was presented, erased, and transformed over the course of the week. In this chapter I juxtapose how gender was supposed to be taught, according to the workshop handbook, with how it was presented and explained by Anna, the AIDS educator, demonstrating the important role that these educators play in knowledge transmission, as well as the ways in which they can transform the information they convey (Wardlow 2012). Jenda - the neologism I use, following Anna's pronunciation, in order to distinguish it from the English term "gender"-can, like gender, be contrasted with sex, but is only loosely tied to it, and is more about acquiring empowering skills (e.g., becoming a nurse) or about moral work on the self (e.g., giving up gambling) than about gendered relations of power or cultural elaborations of the sexed body. A central critique articulated by Anna was that the handbook's discussions of gender, gender inequality, and gender-based violence represented men and women as antagonistically opposed, rather than as complementarily joined or interdependent, which she found inaccurate and unhelpful, and which motivated her efforts to redefine the concept of gender. However, despite her efforts to render gender into a conceptual tool for human betterment (that is, jenda), anger about gender inequality sporadically erupted during the workshop, almost causing it to fall apart.

The ideas about gender presented in the workshop handbook-that sex is biological and gender is social; that gendered tasks are variable around the world, suggesting gender's plastic and arbitrary nature; but that male dominance and female subordination are nevertheless pervasive-are all directly inspired by feminist anthropological research. And despite the problematization of the sex/gender binary by anthropological and other scholarly work, gender nevertheless has canonical status as an emancipatory and empowering concept, particularly when opposed to the constriction and determinism associated with its dyadic partner, biological sex. That an AIDS educator in Papua New Guinea did not find the idea of gender to be emancipatory or empowering challenges hard-won intellectual battles, and suggests the need to examine the kind of conceptual work we assume 
that the sex/gender binary does and why it might not accomplish this same work in other contexts.

\section{A BRIEF HISTORY OF HIV/AIDS EDUCATION IN TARI}

As discussed in chapter 2, Tari, and much of Southern Highlands Province, was going through a tumultuous and sometimes violent socioeconomic decline in the early 20oos. Crime had increased significantly, and almost everyone I knew had stories to tell of being held up by armed gangs or pick-pocketed in the main market. Many NGOs declared Tari a "no-go zone," refusing to send their employees there. In this context, I felt that I could not ethically carry out research without giving something substantial in return. I also hoped that visibly providing a service might make local gangs decide to leave me alone. ${ }^{1}$ So, it was for both self-protective and ethical reasons that I began doing AIDS education in the Tari area in 2004. In a bid to keep electrical power running to its gold mine after a year of ongoing sabotage, Porgera Joint Venture (PJV) had established a small Community Relations office in Tari, employing local men as liaisons to the areas where power pylons were located. Since the local hospital, which had suffered great reductions in its staff, could not spare any resources for my efforts, I eventually proposed that this PJV office assist me. It is perhaps no surprise that it was happy to support my attempts at AIDS education: the two expatriate managers (who worked in rotation, each with approximately two weeks on and two weeks off) were trying to project a benevolent image for PJV, while their Huli staff shared my concern that people in the Tari area were highly vulnerable to HIV.

Choosing to collaborate with a mining company to provide health education might appear questionable (cf. Welker 2016), so I provide some context here. First, my AIDS education effort was never officially supported by PJV: it had no dedicated funding or staff; rather, the expatriate managers provided, when they could spare them, a vehicle, one or more community liaison officers, and a driver. In fact, they didn't initially document the AIDS awareness activities in their reports for fear that their supervisors in Porgera would quash an ad hoc project that had not been formally initiated and approved from above. At that time there was little direct oversight of PJV's small office in Tari, affording the expatriate managers a great deal of autonomy, and they both strongly favored a benevolent developmentalist approach to "asset protection" (that is, protecting the power pylons from sabotage), rather than punitive policing measures. Thus, they often used their discretionary funds to support small local projects, and they perceived AIDS education as an important addition to the services they were providing.

I was also strongly encouraged by my female friends, especially local women's group leaders and the women who ran my guesthouse, to forge ties with this office because, with many government offices and private businesses closed or abandoned, it was the primary source of technical and other resources in Tari. These 
women fully recognized that it was my white status that enabled my easy entrance through the compound's high, guarded gates-when they themselves might have had to wait in line for hours-and they wanted to exploit that status as best they could. Every time I went to the PJV office to organize an AIDS awareness presentation, they armed me with requests for funds, equipment, and technical services (such as fixing generators or leaky water tanks), many of which I was able to help them secure. Moreover, the Huli employees at the office were very concerned about their communities' vulnerability to HIV and lack of information about AIDS, and they continually urged me to increase the number of presentations we were doing. On balance I felt that using my white privilege to obtain assets, influence, and services needed by local women's groups and to provide basic information about AIDS outweighed the problematic possibility that my collaboration with PJV might help burnish its image, precisely at a time when it was trying to build peaceable community relations.

When my 2004 fieldwork was nearing completion, and in the interests of making the work of AIDS education sustainable, the expatriate managers granted my request to send one of my field assistants and some of their staff to Port Moresby for official training and accreditation from the PNG National AIDS Council. A number of these individuals proved to be dedicated, gifted, and cherished AIDS educators who continued to improve their knowledge and skills through participation in numerous HIV/AIDS training programs, and they were later employed by a wide range of NGOs, churches, and businesses, eventually making Hela a place where AIDS education was relatively widespread.

\section{AIDS EDUCATION: DANGEROUS KNOWLEDGE AND THE ANTHROPOLOGY OF IGNORANCE}

When I began new fieldwork in Tari in 2010, the socioeconomic landscape had changed dramatically. PJV still maintained an office in Tari, but, with the construction phase of ExxonMobil's liquid natural gas project at its height, and with government funds pouring in for the new Hela Province, PJV's influence was much diminished in Tari. By then a number of NGOs were engaged in AIDS awareness, as were some churches, and Oil Search (one of the PNG LNG joint venture partners) also employed staff to carry out AIDS education. For the sake of protecting the identity of the AIDS educator who conducted the workshop I discuss in this chapter, I do not identify the organization to which she belonged. This is somewhat problematic since the reader might wonder whether the employing organization-corporate entity, NGO, or religious institution-could exert significant influence over the content presented. And while this is a reasonable question, in fact all the AIDS educators I met or observed received standardized training and certification from the PNG National AIDS Council, and when carrying out AIDS education, they were expected to follow the manual with which 
they were equipped. There was a specific set of topics that they were expected to cover in a particular way, and they were trained in specific exercises, examples, and metaphors for illustrating various points. In other words, much of what they were supposed to do was literally scripted. Thus, the employing agency exerted less influence over workshop content than one might think. That said, one of my aims is to show how AIDS educators do exert translational agency in explicating the content of the AIDS Council manual in their own way, often based on their own reservations about the material.

Anna did, for the most part, follow the handbook quite closely. It is instructive, then, to attend to just where and why she departed from it, which was regarding gender. Arguably, international donor organizations and the Papua New Guinea National AIDS Council might identify gender-related information as what Papua New Guineans-and especially Huli-perhaps need most of all. However, these were the points where Anna most disagreed with the script she was supposed to follow.

In this specific workshop there were twenty participants, ten men and ten women. All of them were or had been married. Two-thirds of them were Huli speakers, and the rest were from other areas of Papua New Guinea and had either married into the area or had been assigned there (e.g., as church pastors). Approximately two-thirds of them were not functionally literate in English, either because they had never attended school or because they had attended long ago and had not since used their knowledge of English. Most of them had been invited because they were leaders in the community (pastors, clan leaders, women's group leaders). The hope was that as leaders they would act as "agents of change," disseminating what they learned to their respective constituencies.

In fact, at the beginning of the workshop the participants were anxious and unsure about whether they wanted to learn about HIV at all. While they were proud to have been chosen, they were also wary about how participation might damage their reputations or confront them with information about sex that they feared could be morally corrupting and that they felt shouldn't be shared widely. The AIDS education workshop-seemingly a straightforward site in which basic biomedical and public health knowledge is conveyed-in this instance turned out to be a complex epistemological and ethical space, where the instructor and participants carefully navigated between the Scylla and Charybdis of knowledge and ignorance. The literature in the "anthropology of ignorance" proves fruitful for analyzing this complex space and how the participants positioned themselves within it. For one thing, this literature suggests that relations of inequality are sustained and reproduced through the discursive production of some people as lacking necessary knowledge. For example, the global AIDS assemblage (Nguyen 2008) operates in part by imagining and discursively producing particular places as urgently in need of absent knowledge about sexual transmission, viruses, immune systems, condoms, and health-promoting gender relations. And the dissemination 
of biomedical health knowledge is therefore assumed to be an inherently valuable endeavor with health- and life-saving potential.

In contrast, anthropologists have observed that not-knowing can be experienced and valued as socially and morally protective. Ilana Gershon and Dhooleka Sarhadi Raj (2000: 3) suggest that it is ethnographically productive to investigate when and why "people actively construct, claim, and maintain ignorance for themselves." Casey High argues, for example, that among the Amazonian Waorani, knowing about shamanism can position the knower as a potential predator in relation to other living beings; "rejecting that knowledge, actively 'unknowing' it is therefore a way of avoiding the predator's perspective and maintaining peaceful relationships with their peers" (Mair, Kelly, and High 2012: 18; High 2012). Moreover, while ignorance or not-knowing is typically presumed to be a kind of empty epistemological space, devoid of content, Mair et al. suggest that it may, in fact, be substantively very meaningful: "There is an ideology, an ethics, and a phenomenology of ignorance," they say (Mair, Kelly, and High 2012: 5; emphasis added). This describes well how Huli understand the customary practice of rigorously not-knowing about sex prior to marriage. The ideology of this not-knowing might be summarized as: sex is physically damaging to young men because it saps them of their vitality and causes premature aging, and it is morally damaging to young women because "opening them up" unleashes their desires for sexual pleasure. Strict ignorance about sex is the only way to prevent these dangers, and marriage the safest way to encompass and control them. The ethics of premarital not-knowing about sex is that community cooperation in sustaining ignorance prevents social harm because premarital sex can embroil young people's families in bitter disputes. The phenomenology of sexual ignorance is the feeling of purity, vitality, and well-being while in the state of not-knowing, and, conversely, the sensation of alarm, violation, or deep embarrassment when one is inappropriately exposed to sexual knowledge. Thus, for example, the one young unmarried man mistakenly invited to participate in this particular AIDS workshop stood up and fled after he skimmed the handbook, which had line drawings of reproductive parts and condoms.

The other participants also expressed concerns about the handbook and seemed to be struggling with two competing ethical orientations towards the workshop. Far from being a meta activity a step or more removed from sex, they suggested, the workshop might itself be a sexual activity, in that it entailed looking at drawings of sexual organs and hearing information about sex, both of which could be sexually arousing. From this perspective, agreeing to be a participant was prurient, something only someone with an unhealthy sexual appetite (a tanga bubu in Huli, or "sex maniac," as some of the participants said) would do. Where researchers, health educators, and science more generally would prefer to see a behavior or practice (e.g., sex) as ontologically distinct from the meta-discourse about it (e.g., "AIDS awareness"), target audiences do not automatically accept that the behavior 
and the discourse are separate and qualitatively different, and they do not necessarily experience the latter as non-sexual. Janna Flora, trying to investigate motivations for suicide in a circumpolar population in Greenland, similarly encountered a reluctance to discuss the topic, because "talking about suicide, sometimes even in general terms, is perceived as dangerous in that it can provoke thoughts of suicide; thoughts that in turn can become directed toward an intended suicide" (Flora 2012: 148). In other words, talk, even when demarcated as a specific meta-discursive genre (e.g., interview, educational presentation) characterized by its own technical lexicon and interactional style, can never truly have a relationship external to the activity it describes or asks about, because talk is always intimately tied to affect, impulse, and desire. There is always the possibility that talk of a forbidden or taboo act might lure the ever-desiring mind closer to the doing of the act.

The other competing moral orientation towards the workshop was that since AIDS was a new and fatal, yet preventable, disease, learning about it was the enlightened, ethical, and necessary thing for leaders to do if they wanted to help their communities. Anna actively encouraged this latter orientation by using a range of framing and participatory strategies to represent workshop participation as the right moral choice. For example, she reminded the participants daily that they were there because, "as good Christians, everyone here is dedicated to saving the lives of people in the community and saving Huli culture." This phrase was intended to accomplish a few things. First, it framed learning about AIDS as religious practice, rather than irreligious prurient desire. Second, it represented the stakes as not only individual lives, but also Huli culture: AIDS could take such a devastating toll on households and communities, Anna suggested, that Huli culture itself would start to disintegrate. She thereby simultaneously appealed to the participants' ethno-nationalist sentiments-sentiments that were strong at the time, because of the creation of the new Hela Province-and assuaged some of their fears. Anna also began and ended each day by calling on one of the male pastors to give a short sermon and by asking one of the women to lead the group in prayer. And she made a point of interpellating the participants almost as children, and cultivating in them a kind of innocence, by starting each session with clapping games or children's songs. In short, acknowledging that the workshop content was morally complicated, she sought to create the space of the workshop, and the participants in it, as virtuous.

\section{TEACHING GENDER}

Much of Stacy Pigg's description of AIDS education workshops in Nepal (2001, 2005) also applies to this workshop, suggesting that such workshops follow much the same procedure everywhere. Anna explained the acronyms HIV and AIDS; the immune system and how HIV disables it; AIDS-related symptoms and disease progression; true and untrue modes of HIV transmission (e.g., sexual 
transmission versus sharing utensils); various means of prevention, including abstinence, fidelity to one partner, and condom use; and the basic workings of the male and female reproductive systems. These topics were organized into sessions, with two or three sessions covered each day. All of the above topics were explained much as the handbook laid out the information.

Where Anna deviated from the script of the handbook was in her explanation of the concept of gender. She understood that gender referred to the culturally variable roles and behaviors that were expected of men and women, but she disagreed with some of the handbook's assertions and implications. She declared, for example, that some of the behaviors or capacities described by the handbook as culturally constructed were, in fact, determined by sex. She also skipped most of the handbook's sections on gender inequality and gender-based violence, feeling that the representation of these topics was reductive, overly inflammatory, and unproductive in the goal of improving marital relations. Finally, she felt that the concept of gender, indicating as it did a large degree of behavioral plasticity, was better deployed to encourage participants to improve themselves morally. In short, when it came to the topics about gender, and only the topics about gender, she took a highly agentive, or even activist, stance in her role as instructor and translator (cf. Tymoczko 2010, Venuti 2008).

\section{Sex or Gender?}

One of the learning objectives in the handbook is for participants to understand the difference between sex and gender, with sex defined as "the biological attributes of being either male or female . . . it is fixed and cannot be changed," and gender defined as "socially constructed. It is made up of learned attributes and behaviours. You are not born with your gender. It is your learned identity. . . .It can be changed" (PNG NAC 2007, 30). The ultimate goal is to show that biologically essentialist notions of men and women often limit women's autonomy, restrict their opportunities, and naturalize expectations of female obedience to male authority, thereby exacerbating women's vulnerability to HIV. Gender as social construction, in contrast, is intended in the manual as an emancipatory concept, an idea that can help workshop participants see that their own assumptions and expectations regarding gender are arbitrary and might be unjust or socially damaging. There is also a hope that, in the intimate space of the workshop, the sharing of participants' own gendered experiences of inequality will inspire greater empathy, perhaps especially in men for women, which will, in turn, facilitate greater critical consciousness about gender.

The handbook explains and illustrates the concepts of gender, gender role stereotypes, and gender-based inequality in multiple ways. For example, it compares breastfeeding as a biological capacity with washing clothes as a gender-based role. And it provides quotations and aphorisms about gender from a range of places around the world, sometimes with explications: 
"Men are gold, women are cloth." This expression, which is used as the title of a report on Cambodian attitudes towards sex and HIV, means that women, like a white cloth, are easily soiled by sex ... whereas men can have repeated sexual experiences and be polished clean, like gold, each time. (PNG NAC 2007, 33)

"I am legally married to my wife and if I have sex with her when she is not ready, that is not rape. A woman is there to serve and dance to the tune of her husband, full stop" - 47-year old man in Tanzania. (PNG NAC 2007, 34)

"Women should wear purdah to ensure that innocent men do not get unnecessarily excited by women's bodies and are not unconsciously forced into becoming rapists . . ."-Malaysian member of Parliament during debate on reform of rape laws. (PNG NAC 2007, 33)

While the written examples regarding gender inequality are taken from all over the world, including wealthy nations such as Canada, the drawn illustrations all depict Papua New Guinean scenarios. They include a bridewealth ceremony, a village scene with women washing clothes and sweeping up the public area, and a man punching his wife while weeping children look on. There is a section that explains the connections between gender roles, gender inequality, and HIV vulnerability by discussing girls' generally lower educational level and access to employment, as well as their lack of power to refuse sex or negotiate safer sex. There are exercises for the participants, with discussion questions about sexual violence (e.g., "Does rape only occur outside of marriage?"; "Are rapists crazy?").

This chapter of the manual covers a wide range of topics in accessible and thought-provoking ways, and while many of the cited statements on gender from around the world might not make much intuitive sense to all Papua New Guinean audiences, they do effectively show that gender inequality is a global issue. More problematically, this chapter of the manual also represents women as oppressed by men, tacitly positioning women and men as antagonists rather than partners. It rhetorically interpellates female participants as victims and creates a space for them to verbalize and share their experiences, but does not create a similar space for male participants. The chapter thus implies that as the dominant gender, men do not experience oppression or marginalization and do not need a space in which to share their gendered or other experiences of inequality.

While embracing the role-plasticity implied by a social constructionist orientation towards gender, Anna also disagreed with some of the specifics in this chapter. She fully supported the idea that women in Papua New Guinea could and should become police officers, pilots, and members of parliament, and she gamely argued, both within and outside the workshop, with Huli men who dismissively mocked this vision of gender equality. She had advocated widely for a bill that would have amended the Papua New Guinea Constitution to reserve twenty-two seats in Parliament for women, and indeed hoped to run for one of these seats (but the bill did not pass). Nevertheless, she also believed that some aspects of biology determined men's and women's behaviors and capacities, though these were not the 
gendered behaviors and capacities that Western/Northern readers might associate with biological essentialism. For example, she told the participants:

This manual gets some things wrong. Some things that this handbook says are gender are really sex. God has designed women in a special way. The reason women are able to keep working all day long is because of their wombs. Men do two or three jobs in a day, and they come home hungry and tired. But women keep going and going and going and are never too tired to work. It's because of a certain kind of magic or medicine that they have in their wombs. It gives them strength. Oh no! Look! I'm revealing women's deepest secrets. Well, I'm not giving away the details. But it is true. It is special medicine or magic in women's wombs that gives them so much energy.

This comment was made in response to the group's discussion about the village scene in the handbook. The drawing of women washing clothes and cleaning up the village seems to imply that the disproportionate amount of domestic labor performed by women is a consequence of inequitable gender relations in Papua New Guinea. Anna rebutted this argument by reformulating women's heavy workload as the exercise of their innate, God-given energy, and thus not to be understood as an outcome of male dominance or privilege. In other words, she affirmed a kind of divine biological essentialism, not in order to argue that women were designed or intended for specific kinds of labor (indeed, she asserted that women and men were equally able to be loving caregivers for children or MPs), but rather to assert their innate superiority to men in terms of endurance. Women had to do more work, she implied, because men simply did not have the capacity to do so.

It should be noted that Anna seemed determined throughout the workshop to avoid angry confrontation between the male and female participants, and she told me that she believed the most fruitful approach to improving Huli gender relations and to reducing HIV vulnerability was to bring men and women together, not put them in opposition to each other. In other words, where the manual hazardously implied that Papua New Guinea's gendered division of labor might be exploitative, Anna reframed the story as one about gender complementarity and innate female stamina.

Anna's desires to avoid confrontation proved difficult, however. One group exercise, in which the participants were asked to break into same-sex groups and create lists of their respective stereotypical gendered tasks, resulted in angry feelings. In normative Huli discourse, many tasks are said to belong quite rigidly to one or the other gender, so this initially seemed to be a straightforward exercise. When the two groups came back together, the men's list included: dig trenches around family territory, build houses, make bows and arrows, clear land of trees and underbrush for cultivation, plant trees, tribal fighting, build fences, negotiate bridewealth, kill and cook pigs, and cut the cooked pork into proper pieces for distribution. The list created by the women was shorter: give birth and breastfeed; care for pigs, dogs, and children; plant and harvest sweet potatoes; make string 
bags; and cut and gather the grasses that make the roof of a house. The men's longer list annoyed the women, since they felt that women do more work than men. The men then made the tactical error of pointing out that men make string bags too (which is true, though it tends to be a highly specialized task that only few men do) and asserting that this task should therefore be added to the men's list as well.

The women, now quite provoked, angrily pointed out the difference between dominant discourse and actual practice, by responding that some of the items on the men's list should also go on the women's list. One woman said, "My husband took another wife, and he doesn't come to our household anymore, so I do many of these male tasks myself. I plant and cut down trees, I kill my own pigs, I cut them up and cook them, and I make my own fences." Another added, "My husband left us, and I haven't seen him in years, and so last year I built my own house. I even got up on top and made the roof myself." For women to engage in this last task is traditionally very taboo, and there were a few loud intakes of breath at this assertion, though no one said anything.

At the heart of these women's performances of male tasks, the reader will have noticed, is male absence. As discussed in chapter 3, there is a long history of male outmigration from the Tari area, which has necessitated changes in women's labor, even if this is not reflected in entrenched normative discourse about gender. Moreover, with the more recent influx of money from resource-extraction projects, especially the LNG, there has been an increase in polygamy in some areas (McIlraith et al. 2012), which has similarly caused an increase in de facto female-headed households, as husbands move to reside with their new wives. Thus, in point of fact, many women perform the tasks on the men's list, or, alternatively, they sell garden produce and other goods in order to make money so that they can pay men to do them. Implied by these women's bitterly proud assertions of female self-sufficiency was an angry critique of male absence and male marital privilege.

The women's interjections helped to make Anna's point that many gendered tasks are learned and are therefore not determined by innate sexual characteristics, but they also heightened the tension in the room since everyone knew that it was male neglect, privilege, and abandonment that necessitated these role changes and contributed to the feminization of rural domestic and agricultural labor. Tensions came to a head when one woman proclaimed loudly, followed by angry mutters of agreement from the rest of the women, "Your list subordinates/belittles us women (List bilong yupela save daunim mipela ol meri)." The Tok Pisin verb she used, daunim (literally, to down someone), can mean either to make someone subservient or to treat them as if they are of lesser value. In other words, she was asserting that by reinscribing normative discourse about gendered tasks, and by creating a long list that made it appear that men did more work than women, the men were discounting women's onerous labor and representing them as less valuable than men. 
Recently divorced herself and used to doing some of the tasks on the men's list, Anna in this instance affirmed the women's experiences of forced self-sufficiency and impressed upon the male participants the difficulties faced by female-headed households. In other words, departing somewhat from her earlier assertions about women's greater capacity for work, Anna indicated that this innate, biologically determined stamina was being pressed into excessive service because of social changes such as divorce, increased polygyny, and male out-migration.

\section{Omitting Gender-Based Violence}

The most significant and disconcerting way in which Anna deviated from the script of the workshop manual took the form of an omission rather than a reframing or correction of the text: although she covered many of the topics in the chapter about gender, she skipped over the sections on gender inequality and gender-based violence. This is particularly remarkable since repeated surveys and ethnographic research in Papua New Guinea (Toft 1985, Dinnen and Ley 200o, Jolly et al. 2012, Human Rights Watch 2015, Biersack et al. 2016) have shown very high rates of domestic and sexual violence in many areas of the country. Moreover, HIV/AIDS policy documents have repeatedly stressed the connection between gender inequality and HIV vulnerability. For example, the National AIDS Council report, Papua New Guinea National HIV and AIDS Strategy, 2011-2015, asserts: "Gender-based violence and sexual violence are endemic in PNG and are a major factor in HIV vulnerability. Interventions which reduce physical and sexual violence against women and girls, and which support survivors of violence, will be urgently scaled-up" (PNG NAC 2010: 34). The U.S. Papua New Guinea Country Operation Plan (COP) 2016 Strategic Direction Summary asserts that "Papua New Guinea ranks 140 out of 155 countries in the 2014 Gender Inequality Index," and states that gender-based violence is "one of the greatest barriers to each of the '90: 90: 90' fast track targets” (PEPFAR 2016: 7-8). ${ }^{2}$ Demographers and ethnographers of the Huli have also documented a high level of gender violence. Analyzing causes of mortality among the Huli in the 1980s, Peter Geoffrey Barss found very high rates of female homicide, for example, and observed: "The endemic severe violence to adult females appears to be unprecedented for a country not under active attack during time of war" (Barss 1991: chapter 7, p. 29). Because of the area's reputation for violent gender relations, Médecins sans frontières initiated a project in Tari in 2009 dedicated to treating family and sexual violence (MSF 2011). In short, if one were to choose a place in Papua New Guinea where education about gender violence would seem most appropriate, Tari would be high on the list, and Anna's omission of this section of the manual was striking.

But Anna had her reasons. She explained to me later that she had been worried that a discussion of gender violence might antagonize the male participants. They could quit the workshop or even shut it down if they so chose. She also wanted to avoid a workshop dynamic in which the female participants heaped blame upon 
men for violent marital relations, because of the possible repercussions afterwards: she did not want the workshop to be the cause of lasting ill will between any of the participants, and she herself did not want to become known as someone who exacerbated marital conflict by encouraging bitterness and resentment.

Equally important, she disagreed with the manual's way of interpellating participants as gendered subjects-especially things like the drawing of the man punching his wife, which depicted men as aggressors and women as victims (cf. Merry 2006). And she deliberately countered this rhetorical strategy of the manual through her own assertions that emphasized agency on the part of both genders. For example, in the one instance in which she did mention gender-based violence-in her discussion of rape as one possible mode of HIV transmission-she asserted that men rape women, but equally that women rape men. By this she meant that some women seduce men and deliberately try to undermine their resolve to be faithful to their wives. Both acts, she felt, were forms of aggression that intentionally removed the capacity of the target to refuse sex. She did not think that they were equal forms of aggression-victims of rape often suffered from shock and other injuries-but she was unhappy that only one of these forms of aggression was addressed in the manual. Her critique suggests that the manual's authors do not fully understand how sexual aggression is understood in various areas of Papua New Guinea, nor do they comprehend the logic of gender complementarity, which assumes that both men and women have agentival capacities.

In short, Anna skimmed the sections on gender inequality and skipped the sections on gender-based violence not only because they were fraught topics that might destabilize the workshop, but also because she felt that the manual simplified highly complex issues and reduced men and women to two-dimensional figures, in which men were fully agentive and culpable, and women were not. "After all," she told me, "it's true that men hit their wives, but it's also true that women hit or even stab their husbands. And women, when they are angry, also tell their husbands that they are worthless trash, and this is a cause of fighting. Maybe we Huli hit each other too much, but the bigger problems are that money is short, and husbands and wives don't know how to talk to each other well."

Anna's skeptical appraisal of the manual resonates to some extent with African and other non-Western feminist critiques of white feminist interventions on behalf of women in postcolonial contexts. Many of these scholars have pointed out the ways in which white feminist discourses about "third world women" often represent them as victims, emphasize male violence against women while obscuring other issues pertinent to women, assume that some customs are imposed by men upon women and are manifestations of their dominance, and willfully ignore the imperialist histories that undermined women's authority in precolonial societies (Mohanty 1984, Amadiume 1987, Mama 1997, Oyewumi 1997).

These scholars also note that white feminists often problematically presume that the epistemologies and strategies that have informed feminist movements in 
the West are the "right" ones and should be adopted globally, ignoring the possibility of alternative philosophies of gender and social action. For example, Philomena Steady, a Sierra Leonean anthropologist, has argued that Western feminism, much like Western liberal humanism more generally, is animated by and organizes itself around concepts of individual autonomy, gender dichotomy, and opposition, while African feminism, in contrast, is organized around the values of gender complementarity and social communalism (Steady 1987; see also Oyewumi 1997). "The language of feminist engagement in Africa (collaborate, negotiate, compromise) runs counter to the language of Western feminist scholarship and engagement (challenge, disrupt, deconstruct, blow apart, etc.)," Obioma Nnaemeka writes. "African feminism challenges through negotiation, accommodation, and compromise" (Nnaemeka 2004: 380). From this perspective, the AIDS workshop manual could be viewed as inspired by a white Western/Northern feminist orientation, in which men and women are adversaries, with men imposing their power through violence. Anna's approach, in contrast, was informed by a philosophy of gender complementarity and collaboration, and she silenced those sections of the manual that assumed and encouraged gendered subject formation based on antagonism.

\section{JENDA AS MORAL WORK ON THE SELF}

As indicated in her observation above that wives play their part in marital violence by, for example, disparaging their husbands as worthless, or by engaging in physical violence themselves, gendered conflict was not just about agency for Anna, but also about culpability, which is to say that it was also about morality. In other words, according to Anna, in many if not all instances, wives as well as husbands said or did something to humiliate or enrage their spouses, actions that were both hurtful and indicative of a need for moral self-reflection and work on the self. From her perspective, it was the rare case in which the tene (root or cause) of marital conflict was singular and locatable in only one spouse's behavior. Fighting or HIV transmission between spouses was a consequence of larger moral problems within a marriage. The key to prevention was thus cultivation of moral improvement, not cultivation of a critical consciousness about gender, as the authors of the workshop manual might have it. At one point during the workshop, Anna therefore articulated her mission not as narrowly focused on HIV prevention, but more broadly on joining men and women together in a shared project of individual, marital, and cultural moral betterment (see also Wardlow 2012).

Jenda-conceptualized as the ability to become a better man or woman-was at the center of her pedagogy. Departing significantly from the workshop manual, Anna's explication of jenda oscillated between being gender-that is, a category that she contrasted with sex and explained as the learned behaviors associated with being male or female-and being something that was completely untethered from biological sex, and was instead a site for ethical work on the self. To illustrate, 
below are ways in which Anna defined or explained jenda, and, in some instances, its difference from sex. As the reader will see, jenda is sometimes juxtaposed to sex, is sometimes almost entirely sex-free, and is sometimes somewhere in between:

"Jenda is what you learn on your life's journey."

"Jenda is important because you can change it. If you are sinful, you can become a religious man. If you are a woman who plays cards, you can change and become a woman who plants sweet potatoes. Jenda is the things you can change about yourself."

"Jenda is learned things-our behaviors, the thoughts we think, the food we make. Can we change these things? [The participants responded: "Yes!"] Sex is different. God designed us in a particular way. Women are always women. Men are always men."

"Jenda is our ability to change our behavior. Jenda is when you are a man who drinks, and you decide to stop being a drinker. Or, when you are a man who participates in tribal fighting, and you decide not to participate in tribal fighting any more. Jenda tells us that we can change, so change! We all need to change, so that as a society we can avoid troubles like tribal fighting, drinking, and HIV/AIDS."

"I can't feed my baby beard hair to make her grow a beard and become a man. She is a girl. This won't change. That is sex. Jenda is what you learn in life that gives you power. For example, you learn to be a pilot or you learn to be a nurse."

In these examples, jenda has an unfixed relationship to biological sex: sometimes it refers to the social roles that sexed bodies come to play, but more often Anna used the concept of jenda to encourage the participants to reflect on their socially or self-destructive practices and to agree that moral improvement was possible and would contribute to the betterment of Huli marriages and Huli society.

Anna also explained jenda as an aspirational pathway-that is, a "journey" through which one might learn valuable knowledge and accrue skills that could "give one power." This understanding of jenda was perhaps inspired by the somewhat misguided examples in the handbook of gender-stereotyped jobs, such as nurses and pilots. In Papua New Guinea, while nurses and pilots are, indeed, gender-stereotyped jobs, they are also careers that are near impossible for most people to obtain. In other words, they are also class-stereotyped jobs. Few children complete grade school, let alone high school or any tertiary education, so any of the workshop participants would have been overjoyed if their children (of either gender) became a nurse or pilot. Thus, as Anna and the participants understood these examples, jenda was not about rigidly entrenched and constraining gender roles, but rather about the possibilities of upward class mobility for a person who dedicated him or herself to accumulating valuable skills and to abstaining from self-defeating habits and behaviors, such as gambling or drinking. In short, Anna took from the manual the idea that gender is that which "is learned" or "can be changed," and put it to work as an agent of hope, moral uplift, and progress. 
This is not to say that jenda was completely unlinked from a notion of gender as learned and expected sex role. Anna also deployed her concept of jenda to introduce the idea that spouses should consider and openly communicate about gender role flexibility in marriage. As she explained it:

What each couple needs to do is figure out what they specialize in. That's jenda. If the wife is not a specialist in cooking, her husband should help her, and not get angry. He should not assume she is an expert in cooking just because she is a woman. Maybe she never learned to cook-that's jenda. Or me, I'm an expert in cutting up roasted pigs and distributing the pieces appropriately. I know that men usually do this job, but I'm very good at it, better than my husband, so I do this in my family.

Here, jenda-used by Anna to mean both culturally defined gendered social roles and individuals' innate, but changeable, skills, habits, and propensities-creates a context in which a husband might be willing to abdicate a prestigious social role (e.g., cutting up a roasted pig and distributing the portions to guests) if his wife happens to be more adept at the task. Both male privilege and female duty, are, to some extent, subtly redefined here as gender-free talents or aptitudes. The concept of jenda, as explained by Anna, is an emancipatory and empowering one, but it operates by creating a space where husbands and wives can discuss their aptitudes and rearrange their tasks accordingly, rather than abide by rigid customary roles. Also notable here is Anna's attempt to guide the workshop participants in one aspect of building a companionate marriage-that is, by setting aside customary dictates and instead verbally negotiating which spouse will do what tasks.

\section{THE RETURN OF THE REPRESSED: GENDER CONFLICT ERUPTS}

Anna's attempts to recruit the participants into jenda as a modern, aspirational, moral project did not completely succeed in containing or silencing gender inequality in the workshop. The gender-role list-making session was just one of a number of moments when the participants became upset. On the second day, a male clinician working in the region, but from another area of Papua New Guinea, came to the workshop to speak to the participants about sexual health. He was nervous, and perhaps that explains why his presentation quickly devolved into an emotional outburst about Huli women's lack of sexual hygiene. The number of Huli women he had examined who had severe, untreated, and foul-smelling vaginal infections was awful, he told the participants; he had never seen anything like it in his previous assignments. His disgust and distress were plain. His speech sped up and rose in pitch. The participants all looked at the floor, but I could see that some faces expressed embarrassment, anger, or revulsion. His repeated mention of the foul-smelling vaginal discharge he encountered seemed to paralyze them. "You 
Huli women," he concluded, "you need to learn to wash better after sex." Finally the session ended and we broke for tea.

Drawing on Foucault, Charles Briggs has argued that authoritative biomedical knowledge is a powerful mode of governmentality, shaping individual conduct, producing health-oriented subjectivities, and defining citizenship in relation to this authoritative knowledge:

$[\mathrm{H}]$ ealth becomes an ethical imperative, requiring individuals to regulate their behavior and reshape their selves in keeping with new medical knowledge. Those who seem to succeed acquire the status of sanitary citizens . . . individuals deemed to possess modern medical understandings of the body, health, and illness, practice hygiene, and depend on doctors and nurses when they are sick. ... People who are judged to be incapable of adopting this modern medical relationship to the body, hygiene, illness, and healing-or who refuse to do so-become unsanitary subjects. (Briggs 2005: 272; see also Briggs with Mantini-Briggs 2004)

This knowledge is unevenly distributed, with some actors designated as "producers of knowledge, others like translators and disseminators, others like receivers, and some simply out of the game" (Briggs 2005: 274; see also Andersen 2017).

Thus far, the female participants in the workshop with their male counterparts had embodied the role of "receivers", a role that positioned them comfortably on the path to sanitary citizenship. Indeed, arguably this is one function of AIDS awareness and other health-related workshops: to select members of an unsanitary subject demographic, offer them the possibility of improving their position in relation to authoritative biomedical knowledge, and thereby hold out the promise of sanitary citizenship and the privileges it confers. But when the male health worker addressed the female participants as "You Huli women" and attributed his caseload of sexual health problems to their lack of hygiene, they were abruptly evicted from sanitary citizenship. In other words, sanitary citizenship was not only ethnicized, with the Huli singled out as less hygienic than other cultural groups, but also gendered. Sitting side by side, receiving the same biomedical knowledge, it was the women, not the men, who were scolded as dirty and ignorant.

I found myself, sitting on the floor, legs crossed, feeling suddenly too aware of my own genitals, wondering if other women in the room were feeling that way too, and thinking about the many times I've experienced yeast infections in Papua New Guinea because my underwear wouldn't dry during the rainy season or because the guesthouse's water tank was broken, and it was hard to stay clean. And then I thought about sex and women's lesser control over when it happens, and how difficult it would be to wash afterwards if you lived in a bush house with no running water and you weren't willing to stumble down to the nearest stream in the middle of the night. And then I thought that the health worker, without any laboratory facilities, had no means of precisely diagnosing the infections he encountered, and that many of them were likely transmitted sexually to his female 
patients from their husbands, and no amount of washing after sex was going to prevent those.

Indeed, it is worth pointing out that this instance of producing an ethnicized and gendered unsanitary subject was based on the deployment of inaccurate biomedical knowledge. Much as Briggs suggests, it was the health worker's designation as an implementer and disseminator of biomedical knowledge, and his clearly superior standing as a sanitary citizen, that authorized his flawed and biased usage of this knowledge. In short, I thought about how gender inequality intersects with lack of sanitation infrastructure and female reproductive physiology to produce sexually transmitted infections in women, who were then rebuked as diseased, dirty, and irresponsible in front of their male community leader peers. It was, for me, and I suspect for many of the female participants (who, uncharacteristically, were completely silent during the tea break), a humiliating gendered moment, not a jenda moment.

Gender inequality created "ugly feelings" (Ngai 2007) in the workshop again on the fourth day, shortly after the gender-role list-making exercise. One of the male participants rather sanctimoniously announced that one health issue they hadn't discussed yet was women's practice of handing off their babies to other women. "We men don't like that." There was silence. And then one woman responded carefully, "Sometimes we have to hand our baby to another woman if there's something we need to do-like buy something at the market. Sometimes we can't carry a baby and do other things at the same time." "But you don't know what diseases those women might have. It is really unhealthy for you to hand our babies to other women." More silence. Then another woman quite testily said, "Well, if you men would agree to carry your own babies, we wouldn't have to worry about that." "But this is against Huli custom. You know that men do not carry babies. It is unhealthy." "No one believes that anymore. You men carry your babies when you are at home. You just don't want to do it in public because you worry that other men will make fun of you and gossip that you are acting like a woman." "Yes," another man interjected angrily, "this is true. How would it look if a man is carrying his young children while his wife walks around with her hands free as if she is the man? And most of the time you women don't have something you need to do-you just want to go talk and laugh with your friends." "And that's not a good reason?!" "No, that's not a good reason!" As one might imagine, the participants' voices became louder and angrier.

Anna jumped in to assert that her husband had often carried their young children if she had specific things she needed to buy at the market, but the participants talked over her and began yelling. Anna tried to bring things to a close with another comment about jenda, and how this was another example of how couples needed to decide together which customs to follow and how to allocate various household responsibilities. But most of the men were adamant that how a man was perceived by his peers-and especially being perceived as appropriately 
masculine by having his hands free and not being feminized by childcare-took precedence over other considerations, because it could affect his political and economic relations with other men. The women remained adamant that if men were not willing to carry their own children in public, they would continue to hand them over to female friends as they saw fit.

I was nonplussed. This was what made the participants most upset-so upset that they were yelling at each other? Not the male and female condom demonstrations? Not the discussions about men marrying multiple wives and still engaging in extramarital sex?

This impromptu discussion had escalated into such a vociferous argument, some participants explained to me, because (1) the men seemed to feel no compunction about taking control of the space of the workshop to chastise the women, and (2) this touched on a number of other issues: men's general disapproval of women's friendships, and their attempts to limit them (Wardlow 2006a); men's attempts to use women's childcare responsibilities to limit and control their freedom of movement; and women's impatience with men's unwillingness to be seen performing domestic roles in public, thus burdening women with stressful multitasking. In other words, this issue affected women's labor, autonomy, and sociality. Since men refused to undertake childcare in the public domain, women felt that they had no right to comment on how women managed their many responsibilities.

\section{CONCLUSION}

Discussing humanitarian organizations' medicalization of wartime sexual violence, Miriam Ticktin observes,

Gender relations are relations of power. As both an analytic category and a social process, gender is relational-it has no meaning or existence alone ... gender relations might be relations of domination or subordination, or of mutual respect or interdependence. Whatever the nature of these relations, when we speak of genderbased violence, we imply relations of power. (Ticktin 2011: 254)

Something similar might be said about HIV/AIDS: that when we speak of HIV/ AIDS, we imply relations of power-relations of power that produce gender as difference, category, and experience, thereby creating differences in HIV vulnerability. And yet this is not how gender is explained in the workshop manual. Instead, although attempting to tackle the issues of gender-based inequality and genderbased violence, the manual relies on a dated social-constructionist conceptualization of gender, which is defined simply as "learned attributes and behaviors" that "can be changed" (p. 30). Indeed, some sections of this chapter in the manual can be read as artifacts of anthropological work: anthropology may have questioned and moved beyond a social-constructionist conceptualization of gender, but it clearly has lasting life as an element of health and development projects. 
It was this social-constructionist aspect of the manual, I believe, that created some of the challenges that Anna had to navigate. Gender explained as a relation of power embedded in a matrix of other relations of power (employed/jobless, employer/employee, former colonial ruler/former colonial subject, landowner/ non-landowner, white/black, urban/rural, educated/uneducated) might have created a conceptual space in which the participants could talk about gendered inequality and violence as intersecting with and shaped by other relations of inequality and violence. And this kind of framework-one that recognized men's experiences of humiliation, fear, marginalization, and violence-might have made a discussion of gender-based violence less threatening and more viable. But gender inequality in the manual is presented as women's inequality, without any contextualization regarding men's history of colonial and postcolonial oppression or marginalization. Similarly, the manual takes an ahistorical approach to gender: nowhere does it ask participants to reflect on and discuss how relations between men and women have changed, why, and with what consequences. The manual's ahistorical approach (presumably based on a notion of "culture" as bounded and unchanging) is perhaps especially problematic in a region where such profound socioeconomic changes have occurred, all of which impact gender relations. Thus, Anna was equipped only with a notion of gender as learned and changeable behavior, and she was then expected to lead a discussion about gender-based violence cued by drawings that interpellated female participants as victims of violence, and male participants as the perpetrators. It is not surprising that she declined to embark on this discussion.

The other, related challenge created by the manual was its implicit positioning of men and women as adversaries rather than partners-for example, in the manual's litany of disparaging quotations and aphorisms about gender and its illustration of marital conflict with a drawing of a man punching a collapsing woman, whose eyes are shut. While the intent of these discursive strategies is surely to convey that male dominance is a global issue, and not something that Papua New Guinean women should feel alone in experiencing, the manual seems very much informed by a Northern liberal feminism in which the genders are locked into an antagonistic relationship and, as Saba Mahmood puts it, female agency "is conceptualized on the binary model of subordination and subversion" (Mahmood 2005: 14). In other words, the presumed female sociopolitical subject is an individual whose autonomy is either subordinated by patriarchy or oriented towards subverting it; her agency can either reinforce or resist male dominance, a conceptualization that leaves little space or legitimacy for other intentions, such as cooperation or negotiation between the genders.

Drawing on her own convictions about how best to improve troubled Huli marital relations - an aim she agreed with-Anna resisted this more binary and antagonistic model in the manual, and formulated her own-jenda-which positioned men and women as having shared (though perhaps not equal) culpability 
in the creation of conflict, and shared responsibility for the work of improving marital relations. Here it is important to observe the influential role that workshop educators can play in the health knowledge economy: in Briggs's scheme, they are positioned as disseminators, tasked with informing target audiences about public health knowledge so that it might change their behavior. However, they are also sometimes certain that the scripted strategies for achieving certain goals are wrongheaded, and so, exercising translational agency, they may alter, silence, or speak back to this knowledge. Thus, Anna took the manual's behaviorchange approach —an approach criticized ad nauseam by anthropologists—and appropriated it to urge the participants to work ethically on themselves for the sake of Huli society.

Anna's attempts to recruit the participants to the concept of jenda were only partially successful, however. Women's subordination was reproduced in the workshop (e.g., when the clinician scolded the women, not the men, about sexual hygiene), and anger about male privileges (to marry polygynously, to walk "hands free" in public, to publicly chastise women) rose to the surface and erupted sporadically. Huli marital relations are, in fact, often marked by strife, and listing gender-stereotyped tasks is not going to go very far in confronting the distressing dimensions of marriage. A more intersectional approach that enabled participants to discuss gender relations in the context of other relations of power and inequality might better enable participants to engage in challenging and painful discussions. 